\title{
Paradigma Pendidikan Profetik dalam Konsep Pendidikan Ki Hajar Dewantara dan Aktualisasinya di Era Disrupsi
}

\author{
Rahmat Hidayat ${ }^{1}$ \\ ${ }^{1}$ UIN Sunan Kalijaga Yogyakarta \\ ${ }^{1}$ skriptor.rhd40@gmail.com
}

\begin{abstract}
The colonial education system that was authoritarian, secularistic and materialistic was still prevalent in national education activities. As a result, today's generation of nations has experienced industrial objectivation, dehumanization, moral decadence, and self-alignment from its socio-cultural effects as a result of national education that sided with market interests (capitalist and materialist). This article seeks to analyze the values of the Pancadarma Taman Siswa Ki Hajar Dewantara which underlie the idea of humanist-religious education. The idea has paradigmatic relevance with the ideals of prophetic education which are explored into three pillars namely humanization (amar ma'ruf), liberation (nahi munkar), and transcendence (al-iman billah). This research is analytical-descriptive using Kuntowijoyo's Social Ethics concept to explore prophetic epistemology in Ki Hajar Dewantara's educational concept. This research resulted in the finding that the Pancadarma Taman Siswa concept required an educational system capable of returning children to their natural self as independent and cultured human beings, as well as arousing transcendental awareness. Pancadarma Taman Siswa installs students as independent individual and social subjects in accordance with human nature (humanization). On the other hand, Ki Hajar Dewantara's education wish for liberation of the world of education from the grip of the industry which adjusts various structural oppressions in society (liberation). Then, Pancadarma positions religion as an objective source of ethics and truth so that all educational activities are only dedicated to humanity and the advancement of civilization.
\end{abstract}

Key Words: Humanist-Religious Education, Ki. Hajar Dewantara, Pancadarma, Prophetic Education

\begin{abstract}
Abstrak
Sistem pendidikan kolonial yang otoriter, sekularistik dan materialistik masih menjangkit dalam aktivitas pendidikan nasional. Akibatnya, generasi bangsa hari ini mengalami objektivasi industri, dehumanisasi, dekandensi moral, serta alienasi diri dari sosio-kulturalnya akibat pendidikan bangsa yang berpihak kepada kepentingan pasar (kapitalis dan meterialis). Artikel ini berupaya menganalisis nilai Pancadarma Taman Siswa Ki Hajar Dewantara yang mendasari gagasan pendidikan humanisreligius. Gagasannya memiliki relevansi paradigmatik dengan cita-cita pendidikan profetik yang dieksplorasi ke dalam tiga pilar yakni humanisasi (amar ma'ruf), liberasi (nahi munkar) dan transendesi (al-iman billah). Penelitian ini bersifat analisis deskriptif menggunakan konsep etika sosial profetik Kuntowijoyo untuk mengeksplorasi epistemologi profetik dalam konsep pendidikan Ki Hajar Dewantara.
\end{abstract}


Penelitian ini menghasilkan temuan bahwa konsep Pancadarma Taman Siswa menghendaki sebuah sistem pendidikan yang mampu mengembalikan anak kepada kodrat dirinya sebagai manusia merdeka dan berbudaya, serta menggugah kesadaran transendental. Pancadarma Taman Siswa berupaya memosisikan anak didik sebagai subjek individu dan sosial yang merdeka sesuai fitrah kemanusiaan (humanisasi). Di sisi lain, pendidikan Ki Hajar Dewantara menghendaki pembebasan dunia pendidikan dari cengkraman industri yang menuaikan beragam penindasan struktural dalam masyarakat (liberasi). Kemudian, Pancadarma memposisikan agama sebagai sumber etika dan kebenaran objektif sehingga segala aktivitas pendidikan hanya didedikasikan untuk kemanusiaan dan kemajuan peradaban.

Kata Kunci: Ki. Hajar Dewantara, Pancadarma, Pendidikan Humanis-Religius, Pendidikan Profetik, Pancadarma

\section{Pendahuluan}

Baru-baru ini, Nadiem Makarim, Menteri Pendidikan dan Kebudayaan Indonesia menggaungkan reformasi pendidikan nasional dengan konsep "Merdeka Belajar". Dalam konsep ini, pendidikan harus mampu memfasilitasi terjadinya proses belajar yang humanis dengan memosisikan peserta didik sebagai subjek yang merdeka. Seringkali proses pembelajaran formal memandang peserta didik sebagai objek yang dipersiapkan untuk melayani kepentingan pasar. Lembaga pendidikan layaknya pabrik yang mempersiapkan para pekerja. Orientasi pasar melahirkan sistem pendidikan yang sekuler dan materialistik sehingga anak didik mengalami alienasi baik secara individual dan kultural (dehumanisasi).

Hingga hari ini, aktivitas belajar mengajar di kelas hanya menekankan aspek kognitif semata dengan basis angka-angka sebagai rujukan utama mengukur kompetensi peserta didik. Nilai angka tidak menjamin kesiapan peserta didik dalam berkarya dan tidak mengindikasikan kematangan karakter anak untuk menghadapi realitas kehidupan. Belum lagi, persoalan kapitalisasi biaya pendidikan, birokratisasi yang alot dan sistem pendidikan sekularistik yang mencerabut dunia pendidikan dari akar spiritual dan lingkungan sosialnya. Pendidikan hari ini gersang dari pembentukan karakter anak.

Akibatnya, tidak sedikit generasi muda bangsa ini yang terjebak pada persoalan dekadensi moral. Tidak heran pula, apabila output yang dilahirkan oleh sistem pendidikan yang kapitalistik dan sekularistik, adalah pribadi-pribadi koruptif, kapitalis, dan sekularis. Mereka pun menjadi robot yang tidak peka dengan persoalan lingkungannya. Untuk itu, Ki Hajar Dewantara dalam konsep pendidikannya menawarkan perspektif humanisme-religius untuk mengenalkan peserta didik kepada jati dirinya sebagai manusia. Menurutnya, setiap peserta didik merupakan makhluk merdeka yang memiliki alamnya sendiri sehingga tidak patut jika mereka diobjektivasi layaknya mesin atau robot. Ia menghendaki anak didik menjadi manusia otonom dan sadar diri akan dirinya, yang terlepas dari beragam tekanan dan penindasan baik fisik maupun psikologis. ${ }^{1}$

Gagasan Ki Hajar Dewantara tentang gagasan Pancadarma Taman Siswa mengusung integralisme pendidikan (humanisme-religius), selaras dengan

\footnotetext{
${ }^{1}$ Moh. Yamin, Menggugat Pendidikan Indonesia, Belajar Dari Paulo Freire Dan Ki Hajar Dewantara (Yogyakarta: Ar-Ruzz Media, 2009), 159.
} 
weltanschauung Indonesia dalam dunia pendidikan nasional. ${ }^{2}$ Kelima nilai pendidikan Ki Hajar Dewantara memuat citacita etik yang selaras dengan misi kenabian yakni menyempurnakan akhlak (moral) manusia dan menebarkan rahmat bagi semesta. Dalam realisasinya, pendidikan hendaknya mengusung prinsip humanisasi, liberasi dan transendesi. Ketiga prinsip tersebut adalah cita-cita profetik yang diderivasi dari QS. Ali Imron: 110, yang artinya "Engkau adalah umat terbaik yang diturunkan ke tangah-tengah kehidupan manusia untuk menegakkan kebaikan, mencegah kemunkaran dan beriman kepada Allah". ${ }^{3}$

Berdasarkan uraian masalah di atas tampak bahwa konsep pendidikan Ki Hajar Dewantara memuat cita-cita profetik tertentu selaras dengan falsafah Pancasila yang menghendaki humanisasi, liberasi, dan transendesi. Secara substantif, gagasan pendidikannya menghendaki terbentuknya kecerdasan secara utuh dalam diri peserta didik yang mencakup kecerdasaan intelektual, kecerdasan emosional, dan kecerdasan spiritual. Untuk itu, artikel ini membahas dua persoalan mendasar yakni Bagaimana bangunan epistemologis pendidikan profetik dalam gagasan pendidikan Ki Hajar Dewantara? Bagaimana implementasinya di era disrupsi?

\section{Metode Penelitian}

Penelitian ini menggunakan telaah pustaka (library research). Data diperoleh melalui sumber tertulis berupa buku, dokumen, dan artikel. Karya Ki Hajar Dewantara yang berjudul Menuju Manusia

${ }^{2}$ H.A.R Tilaar, Pedagogik Teoritis Untuk Indonesia (Jakarta: Kompas, 2015), 81.

${ }^{3}$ Kuntowijoyo, Islam Sebagai Ilmu: Epistemologi, Metodologi, Dan Etika (Yogyakarta: Tiara Wacana, 2006), 87.
Merdeka menjadi sumber primer dalam penelitian ini. Subjek penelitian ini adalah pemikiran pendidikan Ki Hajar Dewantara, sedangkan objek penelitian ini adalah epistemologi profetik dalam gagasan pendidikan Ki Hajar Dewantara dan implementasinya di era distrupsi.

Penelitian bersifat analisis deskriptif dengan menggunakan pendekatan sejarah pemikiran. Menurut Roland N Stromberg dalam Kuntowijoyo, pendekatan sejarah pemikiran merupakan studi tentang peran pemikiran seorang tokoh yang memiliki pengaruh terhadap peristiwa sejarah. ${ }^{4}$ Pemikiran Ki Hajar Dewantara dalam bidang pendidikan karakter dan kritis memiliki pengaruh yang besar terhadap kemerdekaan budaya dari hegemoni kolonial. Konsep pendidikan humanis-religiusnya mendeklarasikan spirit perlawanan terhadap sistem pendidikan kolonial yang sekularistik, hegemonik dan materialistik. Sampai saat ini, paradigma pendidikan kolonial masih tumbuh sebagai benalu dalam pendidikan nasional.

Ada dua hal yang menjadi pokok sorotan pendekatan sejarah pemikiran yakni siapa pelaku dan apa tugas sejarah pemikiran. ${ }^{5}$ Sebuah gagasan atau pemikiran lahir dari individu tunggal. Dalam konteks ini, Ki Hajar Dewantara menjadi pencetus konsep pendidikan humanistik melalui gerakan Taman Siswanya. Kemudian, pemikirannya memiliki pengaruh besar dalam mengubah orientasi pendidikan nasional.

Selanjutnya, peneliti menggunakan konsep Etika Sosial Profetik Kuntowijoyo untuk menggali epistemologi profetik dalam

\footnotetext{
${ }^{4}$ Kuntowijoyo, Metodologi Sejarah, Edisi Kedua (Yogyakarta: Tiara Wacana, 2003), 190-191.

${ }^{5}$ Kuntowijoyo, Islam Sebagai Ilmu: Epistemologi, Metodologi, Dan Etika, 53.
} 
konsep Pancadarma dan Sistem Among Ki Hajar Dewantara yang merepresentasikan pendidikan humanis-religius. Menurut Kuntowijoyo terdapat tiga unsur yang menjadi orientasi etika sosial profetik yakni humanisasi, liberasi dan transendensi. Dalam kerangka pendidikan, humanisasi artinya memanusiakan peserta didik dan guru, menghilangkan kebendaan, ketergantungan, kekerasan dan kebencian dalam dunia pendidikan.

Liberasi dalam pendidikan dipahami sebagai pembebasan pendidikan dari birokratisasi yang ketat, dominasi struktur, serta membebaskan masyarakat dari kemiskinan dan penindasan. Prinsip transendensi dalam pendidikan berupaya menempatkan wahyu sebagai sumber nilai dan sumber pengetahuan, menggugah kesadaran spiritual dan religius dalam jiwa murid dan semua aktivitas pendidikan diniatkan untuk mendapatkan rida-Nya, tidak hanya berorientasi pada tujuan materil semata.

\section{Hasil Penelitian dan Pembahasan Biografi Singkat Ki Hajar Dewantara}

Ki Hajar Dewantara dinobatkan sebagai pemikir dan tokoh pendidikan nasional yang menggaungkan konsep pendidikan humanis, kritis, dan religius. Pendidikan integralistik Ki Hajar Dewantara membuatnya dikenang sebagai Bapak Pendidikan Indonesia. Di sisi lain, ia adalah pejuang kemerdekaan Indonesia yang concern di bidang pendidikan. Secara konsisten, dia mengkritik pendidikan kolonial yang sekular dan tidak humanis. Ki Hajar, selalu mencoba menawarkan solusi ilmiah dan rasional guna perbaikan pendidikan yang mengarah pada pendidikan

Ki Hajar Dewantara lahir di Yogyakarta, pada 2 Mei 1889. Semasa kecil, ia bernama Soewardi Soeryaningrat. Sebagai keturunan bangsawan, ia mendapat gelar Raden Mas (RM), yang kemudian nama lengkapnya Raden Mas Soewardi Soeryaningrat. Kata terakhir dari nama kecil Ki Hajar Dewantara merujuk pada nama ayahnya yang bernama K.P.H. Soeryaningrat. ${ }^{6}$ Ayahnya merupakan putra Paku Alam III sedangkan ibunya bernama Raden Ayu Sandiyah yang merupakan buyut dari Nyai Ageng Serang, seorang keturunan dari Sunan Kalijaga. ${ }^{7}$ Kemudian, pada usia 39 tahun, Raden Mas Soewardi Soeryaningrat berganti nama menjadi $\mathrm{Ki}$ Hajar Dewantara. Pada 4 November 1907, Ki Hajar Dewantara menikah dengan R.A. Soetartinah. Keduanya adalah cucu dari Sri Paku Alam III. Pernikahannya diresmikan berdasarkan adat keraton di Puri Suryaningratan Yogyakarta. ${ }^{8}$

Secara kepribadian, Ki Hajar Dewantara merupakan sosok yang kreatif, dinamis, jujur, sederhana, konsisten, konsekuen, berani dan nasionalis. Lingkungan hidup pada kecil Ki Hajar Dewantara memiliki pengaruh yang sangat besar pada jiwanya yang sangat peka terhadap kesenian dan nilai-nilai kultur Jawa maupun religius. Kultur keraton yang melingkupinya berhasil menanamkan nilainilai spiritual Jawa pada dirinya. Di sisi lain, lingkungan bangsawan yang mengitari kehidupan Ki Hajar Dewantara memberinya

\footnotetext{
${ }^{6}$ Budiono, "Pendidikan Humanistik Ki Hajar Dewantara Dalam Perspektif Pendidikan Islam," Intelektual: Jurnal Pendidikan Islam 7 (2017): 47.

${ }^{7}$ Suparto Rahardjo, Biografi Singkat Ki. Hajar Dewantara, 1889-1959 (Yogyakarta: Garasi, 2009), 6.

${ }^{8}$ Hah Harahap dan Bambang Sokawati Dewantara, Ki Hajar Dewantara Dan Kawan-Kawan, Ditangkap, Dipenjara, Dan Diasingkan (Jakarta: Gunung Aguna, 1980), 12.
} 
peluang besar untuk mencicipi manisnya dunia pendidikan setinggi-tingginya.

Selain mendapatkan pendidikan di lingkungan Istana Paku Alam, Ki Hajar Dewantara juga mendapatkan pendidikan agama dari Pesantren Kalasan yang diasuh oleh KH. Abdurrahman. Selain pendidikan informal, $\mathrm{Ki}$ Hajar Dewantara juga mengeyam pendidikan formal di Europeesche Legere School (ELS), sekolah rendah untuk anak-anak Eropa, Sekolah Dasar Belanda III, Kweek School (Sekolah Guru) di Yogyakarta, dan STOVIA School Tot Opvoeding Van Indische Artsen (STOVIA) yaitu sekolah kedokteran yang berada di Jakarta. Akan tetapi, beasiswa pendidikannya di STOVIA terpaksa dihentikan lantaran Ki Hajar Dewantara sakit selama 4 bulan. ${ }^{9}$

Pendiri Taman Siswa ini juga dikenal sebagai politisi dan jurnalis handal. Ia bergabung dalam organisasi Budi Utomo dan menjadi anggota Indische Partij bersama Douwes Dekker pada 1912. Pada tahun yang sama, ia bersama Douwes Dekker mengasuh Surat Kabar Harian De Express di Bandung. Dia juga menjadi jurnalis di beberapa surat kabar di antaranya Oetoesan Hindia di Surabaya, Tjahaja Timoer di Malang, Midden Java (Bahasa Belanda) dan Sedyotomo (Bahasa Jawa) di Yogyakarta. Karena keterlibatannya dalam politik dan sikap kritisnya terhadap pemerintahan Belanda, Ki Hajar diasingkan di Negeri Belanda pada $1913 .{ }^{10}$

Perjuangannya dalam dunia politik berhasil menginspirasinya untuk mendirikan

${ }^{9}$ Gunawan, Berjuang Tanpa Henti Dan Tak Kenal Lelah Dalam Peringatan 70 Tahun Taman Siswa (Yogyakarta: MLPTS, 1992), 302-303.

${ }^{10}$ Suhartono Wiryopranoto, Perjuangan Ki Hajar Dewantara: Dari Politik Ke Pendidikan, ed. Djoko Marihandono (Jakarta: Museum Kebangkitan Nasional Direktoral Jenderal Kebudauaan Kementerian Pendidikan dan Kebudayaan, 2017), 15.
Perguruan Nasional yang mendidik kaderkader perjuangan melawan para penjajah. Bersama R.A. Soetartinah (istrinya) dan beberapa kawannya seperti Ki Ageng Suryomataram, Ki Pronowodigdo, Ki Cokrodirjo dan sebagainya, Ki Hajar Dewantara mendirikan Nationaal Onderwijs Instituut Taman Siswa, pada 3 Juli 1922. ${ }^{11}$

Ki Hajar Dewantara meninggal dunia pada 26 Apri 1959, di rumahnya Mujamuju Yogyakarta. Sebagai bentuk penghormatan jasanya terhadap bangsa, upacara pemakamannya dipimpin langsung oleh Panglima Kodam Diponegoro Kolonel Soeharto. Pada 28 November 1959, Ki Hajar Dewantara ditetapkan sebagai Pahlawan Nasional. Selanjutnya, pada 16 Desember 1959, pemerintah memperingati tanggal lahir Ki Hajar Dewantara yakni 2 Mei sebagai "Hari Pendidikan Nasional" berdasarkan keputusan Presiden RI Nomor: 316 tahun 1959. ${ }^{12}$

Ki Hajar Dewantara merupakan sosok yang cukup produktif dalam menuliskan gagasan pendidikan dan kebangsaannya. Beberapa karya-karyanya di antaranya: buku bagian pertama: tentang Pendidikan, buku bagian kedua: tentang Kebudayaan, buku bagian ketiga: tentang Politik dan Kemasyarakatan, buku bagian keempat: tentang Riwayat dan Perjuangan Hidup Penulis: Ki Hajar Dewantara.

\section{Konsep Pendidikan Integralistik Ki Hajar Dewantara}

Selama ini pendidikan Indonesia masih mengadopsi konsep pendidikan sekuler ala barat yang berorientasi pada kepentingan kapital. Konsep pendidikan

\footnotetext{
${ }^{11}$ Wiryopranoto, 160-161.

${ }^{12}$ Eka Yanuarti, "Pemikiran Pendidikan Ki. Hajar Dewantara Dan Relevansinya Dengan Kurikulum 13," Jurnal Penelitian 11, no. 2 (2017): 237-66, https://doi.org/10.21043/jupe.v11i2.3489.
} 
Barat modern hanya berorientasi pada kepentingan pasar seringkali menjadi rujukan implementatif pendidikan nasional Indonesia. Tidak dipungkiri, orientasi sekularistik dalam dunia pendidikan menimbulkan sejumlah persoalan moral misalnya tumbuhnya karakter konsumtif dan asosial dalam diri peserta didik, beragam praktik korupsi dalam dunia pendidikan serta dekadensi moral peserta didik. Selama ini, konsep pendidikan karakter Ki Hajar Dewantara mengalami kebekuan aplikatif dalam dunia pendidikan.

Pendidikan hendaknya menjadi jalan masuk anak bangsa untuk mengenali jati diri dan kodratnya sebagai manusia. Akan tetapi, realitas pendidikan hari ini memosisikan anak sebagai objek pengajaran semata dan komoditi yang siap dipasarkan untuk melayani kepentingan industri. Akibatnya, pendidikan hanya mengukur kualitas anak didik hanya pada kecerdasan intelektual semata dengan nilai angka ujian. Guru hanya melihat hasil ujian anak tanpa mengobservasi bagaimana proses belajar, interaksi dan berpikir anak dengan lingkungan sekitarnya.

Ki Hajar Dewantara berpendapat bahwa pendidikan berupaya menuntun segala kekuatan kodrat anak didik agar mereka mencapai keselamatan dan kebahagiaan yang sesungguhnya sebagai manusia (individu) merdeka dan makhluk sosial (bagian dari masyarakat). ${ }^{13}$ Secara substantif, pendidikan harus memanusiakan manusia dan memosisikan anak didik sebagai subjek yang akrab dengan kodrat alam dan lingkungan sosialnya. Pendidikan yang dikehendaki oleh Ki Hajar Dewantara adalah pendidikan yang mampu mengakomodasi kecerdasan intelektual (intellectual quotient), kecerdasan

${ }^{13} \mathrm{Ki}$ Hajar Dewantara, Menuju Manusia Merdeka (Yogyakarta: Leutika, 2009), 03. spiritual (spiritual quotient) dan kecerdasan emosional (emotional qoutient). ${ }^{14}$

Undang-Undang Sistem Pendidikan Nasional Pasal 3 Nomor 20 Tahun 2003 menjelaskan bahwa pendidikan nasional berorientasi mengembangkan potensi peserta didik agar menjadi manusia yang beriman dan bertakwa kepada Tuhan Yang Maha Esa, berakhlak mulia, sehat, berilmu, cakap, kreatif, mandiri, dan menjadi warga negara yang demokratis serta bertanggung jawab. Jelaslah idealisme pendidikan nasional kita tidak berhenti pada pengajaran atau transfer materi di kelas, melainkan menanamkan kepekaan sosial dan spiritual dalam diri anak sehingga kelak ia mampu mengemban amanah umat dan bangsa.

Secara garis besar, konsep pendidikan Ki Hajar Dewantara dapat diekplorasi melalui Sistem Among dan Pancadarma Taman Siswa. Dalam sistem among, guru merupakan dinamo perubahan yang tidak cukup hanya kompeten (profesional) pada bidangnya melainkan juga memiliki jiwa pemimpin yang demokratis. ${ }^{15}$ Dalam sistem among, posisi pendidik menyesuaikan posisi peserta didik dengan perkembangan psikis anak. Ada waktunya guru harus berada di depan peserta didik apabila mereka belum melihat jalan keluar dari masalah yang

\footnotetext{
${ }^{14}$ Kecerdasan intelektual adalah kemampuan yang berkaitan dengan pengetahuan praktis, memori, daya nalar, dan kosakata. Kecerdasan emosional adalah potensi manusia dalam mempelajari keterampilan praktis berdasarkan lima elemen yakni kesadaran diri, motivasi, pengatura dirim emoati dan keahlian dalam membangun relasi sosial dengan orang lain. Sedangkan, kecerdasan spiritual adalah kecerdasan dalam menghadapi dan memecahkan masalah makna dan nilai kehidupan.Ahmad Sultoni, Alef Theria Wasim, and Aris Fauzan, "Development Of Prophetic Intelligence (Phenomenology Study of Religious Transformation)," International Journal of Islamic Educational Psychology (IJIEP) 1, no. 1 (2020): 1224, https://doi.org/10.18196/ijiep.1102.

${ }^{15}$ H.A.R. Tilaar, Pedagogik Teoritis Untuk Indonesia, 152.
} 
dihadapinya (ing ngarso sung tolodo). Pendidik tidak diperkenan memaksakan kehendaknya, ia hanya mendampingi peserta didik agar tidak menyeleweng dari arah yang sebenarnya.

Ketika guru berada di tengah, harus memposisikan dirinya sebagai tonggak penyemangat dan motivator ketika peserta didik mengalami tekanan mental dalam rangka mengembangkan kemerdekaannya baik dari segi intelektual, etik, psikis, maupun fisik (ing madyo mangun karso). Di kala peserta didik memiliki minat pada sesuatu, guru harus berada di belakang untuk memberikan dorongan dan stimulus agar mereka terus maju, pantang menyerah dalam meraih cita-citanyanya (tut wuri handayani). Nilai among yang ketiga ini mengandung filsafat pendidikan yang mendasar yakni pendidikan harus membantu anak dalam memekarkan potensi dan kompetensi anak didik. ${ }^{16}$ Setelah melakukan ketiga pendekatan di atas, pendidik harus menarik diri agar mereka bisa berdiri sendiri sampai pada sebuah titik mereka dapat membuat keputusan dan menentukan pilihan dengan pertimbangan akal budinya yang merdeka.

Guru yang berposisi sebagai pamong dan dinamo perubahan bukan sekedar memberikan instruksi, tugas dan hukuman, tetapi mempersuasi anak dengan memberi motivasi dan teladan kepada mereka. Jelaslah bawah sistem among menghendaki pendidikan yang humanistik. Sebagaimana Paulo Freire, Ki Hajar Dewantara menekankan pentingnya penyadaran peserta didik akan hakikatnya dirinya sebagai manusia yang merdeka.

Konsep pendidikan Ki Hajar Dewantara dapat pula ditemukan pada
Pancadarma Taman Siswa. Kelima nilai ini menjadi fundamen pemikiran pendidikan humanis-religius Ki Hajar Dewantara. Dalam prinsip ini, Ki Hajar Dewantara berhasil mengintegrasikan nilai-nilai humanistik dan nilai-nilai transenden dalam mengaktualisasikan pendidikan yang berkarakter. Berikut penjelasan kelima nilai Pancadarma Taman Siswa: ${ }^{17}$

1. Asas Kodrat Alam. Ki Hajar Dewantara berpandangan bahwa manusia dilahirkan bukan sekedar untuk hidup semata melainkan juga mengembangkan kodrat kemanusiaannya (fitrah) yang dikaruniai oleh Allah SWT (Zat yang Maha Transenden). Kodrat Alam (fitrah) telah dibawa sejak lahir dan berkembang dalam lingkungan si anak. Selain sebagai makhluk individual, anak didik juga merupakan makhluk sosial. Dalam alam sosialnya, anak akan mendapatkan pengalaman yang menyokong potensi dirinya. Dalam asas ini, pendidikan berupaya mendedah dan mempertebal kesadaran ilahiah dan sunnatullah ke dalam diri anak.

2. Asas Kemerdekaan. Ki Hajar Dewantara menilai bahwa manusia dilahirkan sebagai pribadi merdeka. Pribadi merdeka adalah pribadi memiliki daya upaya untuk berdiri diri sendiri dengan kekuatan yang ia dipunya. Kemerdekaan yang dimaksud adalah kemampuan mewujudkan ketertiban dan kedamaian hidup dan penghidupan. Kemerdekaan politik harus disertai dengan kemerdekaan budaya agar kemanusiaan benar-benar mewujud secara paripurna dalam kehidupan bangsa.

${ }^{17} \mathrm{Ki}$ Hadjar Dewantara, Menuju Manusia Merdeka, xii-xiii; H.A.R. Tilaar, Pedagogik Teoritis Untuk Indonesia, 128-129.
${ }^{16}$ K. Bertens, Perspektif Etika Baru: 55 Esai Tentang Masalah Aktual (Yogyakarta: Penerbit Kanisius, 2009), 143. 
3. Asas Kebudayaan. Menurutnya, manusia yang merdeka harus mampu menghargai dan menghormati kemerdekaan orang lain. Kemerdekaan individu harus berpijak pada prinsip kebudayaan. Di sini, pendidikan harus mengenalkan anak pada local culture dan nature untuk menanamkan sikap sosialis dan adaptif di tengah pluralitas kebudayaan Indonesia. Asas ini kemudian akan mengakomodasi terjadinya dialog lintas budaya, musyawarah, gotong-royong dan sikap toleransi. Asas kebudayaan ini memegang prinsip kontinyu yakni kebudayaan lokal dan nasional Indonesia harus dilestarikan oleh generasi bangsa, konvergen yakni pengembangan budaya lokal lewat pemaduan nilai-nilai budaya luar yang positif dan konsentris yakni penyatuan budaya lokal dengan budaya dunia.

4. Asas Kebangsaan. Ki Hajar Dewantara menilai bahwa generasi bangsa selalu lekat dengan tanah air yang menjadi tempat kelahiran mereka. Oleh karena itu, asas kebangsaan menjadi penting ditanamkan dalam diri anak untuk meleburkan ikatan-ikatan primordial ke dalam ikatan kebangsaan yang bersifat plural dan universal. Cinta tanah air (nasionalisme) harus mengakui hak individual dan hak komunal. Dengan demikian, nasionalisme yang dimaksud Ki Hajar Dewantara bukanlah nasionalisme destruktif dan imperialis, melainkan nasionalisme yang mengabdi kepada masyarakat, negara dan kemanusiaan.

5. Asas Kemanusiaan. Asas terakhir ini menegaskan bahwa kemerdekaan individu akan didapatkan melalui kemerdekaan dalam berekspresi, berpikir dan menentukan kemanusiaannya. Dunia pendidikan dapat menjadi ruang untuk mengembangkan kemerdekaan peserta didik. Di sekolah, peserta didik diasah untuk mengenal kerjasama antar sesama, saling mengasihi dan saling menghormati. Oleh karena itu, asas kemanusiaan ini tidak menghendaki adanya kekerasan fisik, verbal atau psikologis dalam dunia pendidikan.

Berdasarkan penjelasan di atas, jelaslah bahwa Ki Hajar Dewantara berhasil mengintegrasikan filsafat humanis dan teosentris dalam aktivitas pendidikan Taman Siswa. Peserta didik lahir membawa fitrah yakni kepercayaan kepada zat yang maha transenden sekaligus ketaatan pada hukum alam (sunnatullah) yang berkelindan dalam kehidupannya. Di sisi lain, ia percaya bahwa fitrah itu tidak hanya kepercayaan kepada zat yang maha esa namun mencakup kemerdekaan dan kemanusiaan. Dari sini, tidak ada dikotomi, diferensiasi dan sekularisasi dalam konsep pendidikan $\mathrm{Ki}$ Hajar Dewantara.

Secara substantif, pemikiran pendidikan Ki Hajar Dewantara bersifat integralistik. Konsep pendidikannya merupakan antitesis atas konsep pendidikan sekuler yang cendrung materialistik dan konsep pendidikan konservatif. Filsafat progresivisme dan eksistensialisme yang mengakui peserta didik sebagai subjek selaras dengan aktivisme pendidikan $\mathrm{Ki}$ Hajar Dewantara yang tidak mengindahkan pendidikan yang otoriter. ${ }^{18} \mathrm{Di}$ sisi lain, Ki Hajar Dewantara juga berpijak pada ajaran

${ }^{18}$ Musa Pelu, "Pancadarma Taman Siswa: A Philosophical Reflection of Ki Hajar Dewantara's Thought on The Perspective of Religious-Humanist Education," Journal of History Education and Religious Studies 1, No. 1 (2020): 14, https://jurnal.uns.ac.id/jhers/article/view/43030. 
agama (wahyu) yang menjadi sumber nilai sekaligus sumber pengetahuan.

Dalam realitas pendidikan nasional, sistem dan orientasi sekolah diarahkan untuk mengejar kesuksesan secara materil semata seperi karier, kekuasaan, jabatan, dan uang. Persoalan ini terletak pada basis epistemologis pendidikan Indonesia yang menitik beratkan filosofi antroposentrisme dengan mengenyampingkan filosofi teosentrisme. Distingsi filosofis ini sangat memengaruhi proses dan output pendidikan bangsa. ${ }^{19}$ Karena selama ini, antroposentrisme menjadi warna yang dominan dalam dunia pendidikan Indonesia, tidak heran apabila output pendidikan Indonesia menghasilkan pribadi yang koruptif, amoral, sekuler dan kapitalis.

Pendidikan integralistik yang diusung oleh Ki Hajar Dewantara menempatkan rasio manusia dan wahyu agama dalam posisi yang seimbang dalam bangunan pendidikan nasional. Harapannya, tidak ada lagi diferensiasi ilmu pengetahuan dan sekularisasi pendidikan. Pada tataran praktik, integralisme pendidikan ini berorientasi pada pembentukan kecerdasan anak secara holistik baik kecerdasan intelektual, kecerdasan emosional, dan kecerdasan spritual. Output yang diharapkan oleh pendidikan nasional adalah pribadi religius, humanis, dan nasionalis.

Jelaslah bahwa konsep pendidikan Ki Hajar Dewantara membawa dua konsep sekaligus yakni pendidikan humanis dan pendidikan religius. Integrasi konsep pendidikan tersebut berupaya membangun pendidikan humanistik yang religius sebagai antitesis pendidikan sekuler-materialistik. Pendidikan humanistik mengedepankan

${ }^{19}$ John S. Brubacher, Modern Philosophies of Education (New Delhi: Tat McGraw-Hill Compan, 1978), 188-190. kemandirian dan kemerdekaan individu dengan tidak menyalahi norma-norma dan nilai-nilai universal dalam ajaran agama tertentu. Pendidikan yang memanusiakan manusia tidak kalah pentingnya dengan pendidikan spiritual di tengah krisis multidimensional. Gejala sekularisasi, objektivasi manusia, industrialisasi dan dehumanisasi dalam dunia pendidikan hanya dapat dilawan dengan alternatif paradigma integralisme yang menjadi landasan epistemologis pendidikan profetik.

\section{Filsafat Profetik dalam Aktivisme Pendidikan}

Fenomena sekularisasi, kapitalisasi dan industrialisasi yang melanda dunia intelektual pendidikan nasional telah menjadikan aktivisme pendidikan hari ini menjadi jauh dari jangkaun spiritualitasnya. Sesungguhnya pendidikan merupakan usaha bangsa ini membawa manusia Indonesia keluar dari kejahilian baik secara intelektual maupun moral, dengan membuka tabir aktual-transenden dari sifat alami manusia (humanis). ${ }^{20}$ Namun, nyatanya praktik objektivasi dan dehumanisasi peserta didik menjadi persoalan yang rumit hingga hari ini.

Tercerabutnya dunia pendidikan dari akar spiritualitasnya menyebabkan munculnya generasi yang koruptif dan amoral. Dari sini, filsafat profetik menjadi alternatif untuk mengganti paradigma sekularistik dan materialistik yang menjangkit pada dunia pendidikan kita hari ini. Konsep pendidikan profetik mengacu pada pemikiran ilmu sosial profetik Kuntowijoyo menjadi alternatif untuk membangun konsep pendidikan nasional

${ }^{20}$ Sukri, Trisakti Handayani, dan Agus Tinus, "Analisis Konsep Pemikiran Ki Hajar Dewantara Dalam Perspektif Pendidikan Karakter," Jurnal Civic Hukum 1, No. 1 (2016): 34 , https://doi.org/10.22219/jch.v1i1.10460. 
yang humanis. Istilah "profetik" ini merujuk kepada sosok insan kamil yakni Nabi Muhammad yang dikenal sebagai pemimpin agama, pemimpin politik sekaligus pendidik yang humanis-religius. Pendidikan menjadi media dakwah Nabi untuk merealisasikan misinya sebagai penyuluh, pendidik dan penyempurna akhlak manusia. Nabi sebagai figur ideal dengan sikap jujur dan objektif (siddiq), dapat dipercaya (amanah), cerdas (fathanah), dan menyampaikan risalah kebenaran (tabligh) menjadi sumber inspirasi nilai-nilai karakter dalam aktivisme pendidikan. Dalam pendidikan profetik, peserta didik dicetak menjadi khair al-ummat atau komunitas ideal, bukan hanya ideal secara individual tetapi juga secara komunal. ${ }^{21}$

Menyitir pemikiran Seyyed Hosen Nasr, dalam kerangka kerja profetik, dunia intelektual (pendidikan) seharusnya tidak dipisahkan dari kesuciannya, karena substansi pengetahuan adalah realitas tertinggi. Aktivisme pendidikan berupaya memberikan pengetahuan anak didik akan hakikat dirinya. ${ }^{22}$ Gagasan profetik Kuntowijoyo ini berpijak pada tiga pilar utama yakni mengajak kepada kebaikan (humanisasi/amar ma'ruf), membebaskan manusia dari segala bentuk penindasan (liberasi/nahi munkar), dan kepercayaan kepada Zat yang Maha Transenden sebagai sumber kebenaran (transendesi/al-iman billah). ${ }^{23}$ Tiga pilar itu diderivasi dari ayat QS. Ali Imran, ayat 110 yang mempunyai arti "Engkau adalah umat terbaik yang diturunkan di tengah manusia untuk

\footnotetext{
${ }^{21}$ Moh. Roqib, "Pendidikan Anak Kreatif Perspektif Profetik," Tadrîs 9, no. 1 (2014): 30.

${ }^{22}$ Seyyed Hosein Nasr, Pengetahuan Dan Kesucian, ed. Suharsono (Yogyakarta: Center for Internasional

${ }^{23}$ Kuntowijoyo, Islam Sebagai Ilmu: Epistemologi, Metodologi, Dan Etika, 64.
}

menegakkan kebaikan, mencegah kemungkaran, dan beriman kepada Allah". Humanisasi berarti memanusiakan manusia, menghilangkan kebendaan, ketergantungan, kekerasan dan kebencian dari manusia. ${ }^{24}$ Secara kontekstual, humanisasi dalam pendidikan akan menyiapkan peserta didik yang berkomitmen untuk menjaga persaudaraan di tengah kemajemukan dan mengakui realitas plural ini sebagai emanasi dari zat yang Maha Tunggal. Di sisi lain, prinsip humanisasi dalam dunia pendidikan berupaya mengenalkan peserta didik terhadap jati dirinya sebagai individu merdeka sekaligus bagian dari lingkungan sosialnya. Pendidikan profetik juga tidak menghendaki otoritarianisme pendidikan yang menghalalkan kekerasan. ${ }^{25}$

Adapun liberasi berorientasi pada pembebasan manusia dari kekejaman, kemiskinan struktural, keangkuhan teknologi dan pemerasan kelimpahan. Dalam dunia pendidikan, implementasi nilai liberasi yakni membebaskan dunia pendidikan dari jeratan birokratisasi untuk memberikan ruang inovasi pada guru selama proses pembelajaran. Di sisi lain, prinsip liberasi berupaya membebaskan peserta didik dari segala praktik penindasan baik kultural maupun struktural, misalnya kapitalisasi biaya pendidikan, praktik suap dalam dunia pendidikan, otoritarianisme pendidikan, dan korupsi uang pendidikan. Prinsip ini juga menegaskan bahwa pendidikan harus berpihak pada wong cilik melalui pemberdayaan sosial-ekonomi dan penyuluhan kebudayaan. Kemudian,

\footnotetext{
${ }^{24}$ Kuntowijoyo, Muslim Tanpa Masjid: Esai-Esai Agama, Budaya, Dan Politik Dalam Bingkai Strukturalisme Transendental (Jakarta: Mizan, 2001), 364.

${ }^{25}$ Moh. Roqib, Prophetic Education: Kontekstualisasi FIlsafat Dan Budaya Profetik Dalam Pendidikan (Purwokerto: STAIN Press, 2011), 84.
} 
pendidikan berperan dalam memberantas kebodohan dan keterbelakangan sosial ekonomi yang terjadi dalam masyarakat.

Adapun transendesi berupaya membersihkan diri dengan mengingatkan kembali dimensi transendental yang menjadi fitrah kemanusiaan peserta didik. Dalam konteks pendidikan dipahami sebagai kepercayaan bahwa wahyu tuhan sebagai sumber kebenaran dan sumber nilai. Transendesi sebagai ikatan spiritual mengikat seluruh aktivitas manusia, termasuk pendidikan dengan Tuhan yang Maha Esa. Segala aktivitas fisik atau non-fisik tidak dapat dilepaskan dari kalam Allah yang suci yaitu al-Qur'an. Dalam kerangka kerja pendidikan, transendesi berupaya mengaitkan segala aktivitas pendidikan (baik ilmiah) kepada ajaran kitab suci, melakukan hubungan dengan kosmos dan kosmis sebagai perwujudan dari penasbihan atas keagungan Allah, dan proses belajarmengajar diniatkan untuk mengharapkan rida-Nya. ${ }^{26}$

\section{Paradigma Pendidikan Profetik Dalam Pancadarma Taman Siswa}

Term profetik banyak mengacu kepada pemikiran Kuntowijoyo yang berjasa memperkaya kajian sosiologi berdimensi profetik. Konsep profetik Kuntowijoyo menjunjung tiga misi utama yakni humanisasi (amar ma'ruf), liberasi (nahi munkar) dan transendensi (iman billah). Jika gagasan profetik ini ditarik dalam konteks pendidikan, tiga unsur ini memiliki keselarasan filosofis dengan konsep pendidikan humanis-religius $\mathrm{Ki}$ Hajar Dewantara yang tercermin dalam Pancadarma Taman Siswa. Menurutnya, pendidikan merupakan media untuk mengenal anak didik akan hakikat

${ }^{26}$ Roqib. 79 kemanusiaan, kebudayaan, dan asal-muasal dirinya.

Formulasi etika sosial profetik Kuntowijoyo kentara pula dalam corak pemikiran pendidikan Ki Hajar Dewantara perihal Pancadarma Taman Siswa. Dalam asas kodrat alam dinyatakan bahwa manusia dilahirkan bukan sekedar untuk hidup semata melainkan juga mengembangkan kodrat kemanusiaannya (fitrah) yang dikarunia oleh Allah SWT. Dengan berinteraksi dengan alam, anak akan mendapatkan pengalaman religius-spiritual dengan mengembangkan potensi sosialnya. Dari sini, pendidikan berupaya membentuk pribadi anak yang saleh secara individual dan sosial.

Spirit liberasi juga termuat dalam asas kemerdekaan. Pada asas ini, pendidikan harus membentuk pribadi merdeka yang memiliki daya upaya untuk berdiri sendiri. Kemerdekaan di sini bermakna pembebasan peserta didik dari otoritarianisme pendidikan, kebodohan, keterbelakangan intelektual dan mental. Sedangkan spirit humanisasi dan transendensi terdapat dalam asas kebudayaan. Menurut Ki Hajar Dewantara, kemerdekaan individu harus berpijak pada nilai-nilai kebudayaan nasional rangka menanamkan sikap terbuka di tengah pluralitas kehidupan bangsa. Menurut Ki Hajar Dewantara, beragam pelajaran di sekolah hendaknya diadaptasikan berdasarkan penyatuan nilai-nilai budaya Indonesia baik yang bersumber dari agama (wahyu), adat istiadat, kesusilaan, kesenian, sejarah dan lain-lain. ${ }^{27}$

Agama dalam dunia pendidikan mengisi pengajaran etika dan moral. Melalui pendidikan agama peserta didik mendapatkan rasa penghargaan, cinta dan kesadaran terhadap realitas keagamaan yang majemuk.

${ }^{27} \mathrm{Ki}$ Hadjar Dewantara, Menuju Manusia Merdeka, 46-47. 
Dari sini, asas budaya dalam kerangka pendidikan agama membuka peluang besar terjadinya dialektika, dialog, musyarawah dan spirit toleransi antara umat beragama. Sikap moderat dalam beragama harus dijunjung tinggi oleh setiap peserta didik yang mengenyam pendidikan agama. Pendidikan bercorak multikultural ini berangkat dari argumentasi teologis bahwa kemajemukan hidup merupakan emanasi dari zat yang Maha Esa sekaligus Maha Transenden.

Dalam asas kebangsaan, Ki Hajar Dewantara menegaskan bahwa pendidikan berupaya membangun nasionalisme dalam diri peserta didik. Hal ini tentu untuk meleburkan ikatan-ikatan primordial ke dalam ikatan kebangsaan yang bersifat plural dan universal. Cinta tanah air harus mengakui hak individual dan hak komunal. Dengan demikian, nasionalisme Ki Hajar Dewantara bukanlah nasionalisme yang dekstruktif dan imperialis, melainkan nasionalisme yang mengabdi kepada masyarakat, negara dan kemanusiaan.

Hilangnya ikatan primordial digantikan dengan ikatan kebangsaan yang berbasis spiritual melahirkan sikap kolaboratif, kerjasama, saling tolongmenolong, saling mengasihi dan menghormati antar sesama. Dengan asas kebangsaan ini, peserta didik dapat menentukan dan meneguhkan identitas kemanusiaannya di tengah keberagaman budaya. Oleh karena itu, asas kemanusiaan ini tidak menghendaki adanya kekerasan fisik, verbal atau psikologis dalam dunia pendidikan.

Uraian di atas menegaskan bahwa nilai Pancadarma Taman Siswa memuat citacita profetik yang mengacu kepada pengalaman mendidik Nabi Muhammad. Selain pemimpin agama dan politik, beliau adalah seorang pendidik yang mengedepankan prinsip humanis dan religius. Dalam hal ini, penulis memaparkan tentang paradigma profetik ke dalam Pancadarma Ki Hajar Dewantara merupakan ijtihad ideografik yang berupaya memperkaya pembacaan terhadap konsep pendidikan Ki Hajar Dewantara.

Aktualisasi nilai-nilai Pancadarma dalam konteks pendidikan nasional yang terjebak dalam logika produksi memiliki urgensi tersendiri. Hal ini berorientasi pada reformasi pendidikan agar tidak tercerabut dari akar spiritualitasnya. Pancadarma menjadi titik tolak pemikiran pendidikan humanis-religius yang mengelaborasi dan merefleksikan nilai-nilai etika transendental dalam budaya pendidikan. Ki Hajar Dewantara menjadikan pendidikan sebagai sarana dakwah dalam merealisasikan humanisasi, liberasi dan transendensi. Ketiga unsur ini terformulasikan dalam Pancadarma Taman Siswa yang hendaknya mengembalikan kodrat kemanusiaan anak didik kepada dirinya sendiri serta lingkungan sosialnya.

\section{Implementasinya di Era Disrupsi}

Di era disrupsi, konsep pendidikan $\mathrm{Ki}$ Hajar Dewantara yang membawa kerangka pemikiran profetik menjadi sangat relevan. Mengingat, generasi bangsa kita mulai tercerabut dari akar kebudayaan dan spiritualitasnya, serta banyak dari mereka yang mengalami dehumanisasi dan objektivasi sebagai dampak dari industrialisasi pendidikan. Hal ini menjadikan pendidikan humanis-religius $\mathrm{Ki}$ Hajar Dewantara aktual dan kontekstual. Secara implementatif, pancadarma dapat diaktualisasikan dalam tri pusat pendidikan yakni keluarga, sekolah dan masyarakat. 
Pertama, keluarga sebagai lingkungan sosial pertama anak memiliki peran sentral untuk menanamkan karakter dalam diri anak. Orang tua sebagai murabbi pertama harus mampu memberikan teladan yang kepada anak. Melalui keteladanan orang tua, proses transfer nilai dan pendidikan karakter terjadi secara tidak langsung dalam iklim keluarga. Orang tua adalah role model sekaligus figur penting dalam keluarga yang tidak hanya bertanggungjawab memenuhi kebutuhan material anak, tetapi juga memenuhi kebutuhan intelektual, spiritual dan psikologi anak.

Sebagai guru pertama, orang tua memiliki tanggung jawab untuk membumikan literasi anak di rumah. Literasi tidak hanya dipahami sekedar pengenalan anak kepada dunia baca tulis. Lebih itu, literasi mencakup kemampuan anak dalam mengobservasi, menginterpretasi, dan beradaptasi dengan lingkungannya. Tidak kalah penting, orang tua juga harus memosisikan anak sebagai subjek merdeka. Dalam kerangka ini, orang tua harus melibatkan anak dalam musyawarah keluarga agar pandangan mereka lebih luas dalam memahami persoalan hidup serta menjadikan mereka lebih dewasa dalam menemukan problem solving atas permasalahan yang dihadapinya.

Di sisi lain, orang tua memiliki peran penting mendekatkan dan mengenalkan anak dengan lingkungan sosialnya melalui media silaturahim, gotong-royong dan sebagainya. Ajakan ini pada nantinya akan menumbuhkan sikap empati sosial dalam diri anak. Semua upaya di atas rangka mewujudkan lingkungan keluarga yang ramah anak.

Kedua, sekolah. Sekolah diasumsikan sebagai lembaga pengembangan intelektual dan kepribadian anak secara menyeluruh.
Guru di sekolah memiliki peran sentral untuk mencetak generasi bangsa yang berkarakter, karena guru adalah sosok yang digugu dan ditiru. Menurut Ki Hajar Dewantara, guru merupakan pengemong pendidikan anak. Ia adalah dinamo perubahan yang dituntut memberikan teladan di saat berposisi di depan, memberikan motivasi di tengahtengah peserta didik dan memberikan dorongan dari belakang.

H.A.R. Tilaar menyatakan bahwa di era disrupsi ini masyarakat Indonesia yang termodernkan mengalami perubahan persepsi terhadap sosok guru yang ideal. Pada abad 21, guru mendapat tuntutan formal untuk menjadi sosok yang profesional. Kriteria guru profesional pada abad 21 yakni guru harus memiliki sifat pemimpin, dalam arti guru harus jujur, bekerja keras, berbudi pekerti yang baik, disiplin, sosialis, inovatifkreatif dan kritis. ${ }^{28}$

Selain menguasai bidang keilmuan yang diajarkan kepada para murid, guru harus mampu mengobservasi dan mendalami proses belajar anak sehingga keberhasilan peserta didik tidak semata-mata diukur dari angka-angka. Dengan mendalami proses belajar murid, guru dapat menilai secara holistik kualitas intelektual dan pribadi anak. Kemudian, transformasi oganisasi profesional guru sangat diperlukan rangka menghadirkan sikap penghargaan sosial dari masyarakat dan pemerintah terhadap profesi guru.

Di tengah kehidupan digital yang identik dengan kemajuan teknologi dan informasi, guru harus memiliki kecakapan literasi digital. Hal ini untuk memanfaatkan teknologi modern untuk pengembangan intelektual dan pribadi anak. Perlu dipahami juga, bahwa teknologi informasi hanyalah sarana bukan tujuan dalam proses

${ }^{28}$ Dewantara., 53. 
pembelajaran. Kemudian, guru harus menjadi dinamo perubahan dalam arti guru tidak hanya menjelma sebagai sosok pemberi instruksi, penegak peraturan sekolah dan pemberi hukuman semata. Lebih dari itu, guru harus menjadi role model yang berakhlak mulia, motivator, pendorong dan pembimbing anak dalam mengembangkan kodrat kemanusiaannya.

Pendidikan profetik juga dapat diaktualisasikan melalui kurikulum sekolah. Kurikulum sekolah harus berpijak kepada nilai-nilai Pancasila sebagai fundamen filosofis pendidikan nasional. Di sisi lain, kurikulum yang diterapkan harus berdasarkan pada perkembangan peserta didik. Kurikulum sebagai sarana mencapai tujuan pendidikan harus berada dalam genggaman guru yang profesional. Di sisi lain, kurikulum yang diterapkan harus berlandaskan nilai kebudayaan setempat.

Pusat pendidikan yang ketiga adalah masyarakat. Peserta didik sebagai makhluk sosial dilahirkan dalam suatu keluarga yang menjadi anggota masyarakat. Masyarakat Indonesia telah merepresentasikan realitas kebudayaan yang multikultural. Dari masingmasing budaya yang ada dalam payung Indonesia tentu memiliki nilai-nilai sendiri yang beragam pula. Dari sini, masyarakat memiliki peran penting untuk menanamkan nilai-nilai local wisdom dalam pribadi anak. Secara operasional, masyarakat, idealnya harus mengoptimalisasikan ruang-ruang publik yang tersedia sebagai sarana penyuluhan kebudayaan kepada generasi muda. Misalnya, ruang ibadah (masjid) sebagai ruang publik harus dioptimalisasikan sebagai basis poliferasi literasi agama yang moderat dan humanis.

\section{Kesimpulan}

Paradigma pendidikan profetik dalam Pancadarma Taman Siswa Ki Hajar Dewantara berangkat dari filsafat humanisme-teosentris. Secara konseptual, pemikiran pendidikan Ki Hajar Dewantara tidak menegasikan peran wahyu sebagai patokan kebenaran objektif sekaligus sumber etika. Namun, ia mengintegrasikan rasio dan wahyu sebagai sumber pengetahuan dalam dunia pendidikan. Berbeda dengan pendidikan sekuler yang menempatkan rasio sebagai tumpuan kebenaran yang mutlak dan memisahkan aspek religius dari aktivisme pendidikan. Konsep pendidikan Ki Hajar Dewantara menekankan keseimbangan antara aspek duniawi dan ukhrawi, aspek lahir dan batik, aspek kognitif dan spiritual dalam dunia pendidikan.

Implementasi gagasan Pancadarma Taman Siswa yang mengusung cita-cita profetik hendaknya diaktualisasikan dalam tripusat pendidikan yakni keluarga, sekolah, dan masyarakat. Pertama, ketiganya harus memosisikan anak sebagai subjek merdeka. Kedua, para penggerak pendidikan harus mampu memberikan teladan yang baik kepada anak. Ketiga, segala aktivitas pendidikan yang berkelindan di dalamnya hendaknya berangkat dari nilai-nilai kebudayaan secara menyeluruh seperti nilai yang bersumber dari agama (wahyu), adat istiadat, kesenian, kesusilaan dan kesejarahan.

\section{Daftar Pustaka}

Bertens, K. Perspektif Etika Baru: 55 Esai Tentang Masalah Aktual. Yogyakarta: Penerbit Kanisius, 2009.

Brubacher, John S. Modern Philosophies of Education. New Delhi: Tat McGrawHill Compan, 1978.

Budiono. "Pendidikan Humanistik Ki Hajar 
Dewantara Dalam Perspektif Pendidikan Islam." Intelektual: Jurnal Pendidikan Islam 7 (2017): 42-53.

Dewantara, Hah Harahap dan Bambang Sokawati. Ki Hajar Dewantara Dan Kawan-Kawan, Ditangkap, Dipenjara, Dan Diasingkan. Jakarta: Gunung Aguna, 1980.

Dewantara, Ki Hajar. Menuju Manusia Merdeka. Yogyakarta: Leutika, 2009.

Gunawan. Berjuang Tanpa Henti Dan Tak Kenal Lelah Dalam Peringatan 70 Tahun Taman Siswa. Yogyakarta: MLPTS, 1992.

Kuntowijoyo. Islam Sebagai Ilmu: Epistemologi, Metodologi, Dan Etika. Yogyakarta: Tiara Wacana, 2006.

. Metodologi Sejarah. Edisi Kedu. Yogyakarta: Tiara Wacana, 2003.

-. Muslim Tanpa Masjid: Esai-Esai Agama, Budaya, Dan Politik Dalam Bingkai Strukturalisme Transendental. Jakarta: Mizan, 2001.

Nasr, Seyyed Hosein. Pengetahuan Dan Kesucian. Edited by Suharsono. Yogyakarta: Center for Internasional Islamic Studies, 1997.

Pelu, Musa. "Pancadarma Taman Siswa: A Philosophical Reflection of $\mathrm{Ki}$ Hajar Dewantara's Thought on The Perspective of Religious-Humanist Education." Journal of History Education and Religious Studies 1, no. 1 (2020): 11-20. https://jurnal.uns.ac.id/jhers/article/view 143030.

Rahardjo, Suparto. Biograf Singkat Ki. Hajar Dewantara, 1889-1959. Yogyakarta: Garasi, 2009.

Roqib, Moh. "Pendidikan Anak Kreatif Perspektif Profetik." Tadrîs 9, no. 1 (2014): 17-33.

Prophetic Education: Kontekstualisasi FIlsafat Dan Budaya Profetik Dalam Pendidikan.
Purwokerto: STAIN Press, 2011.

Sukri, Sukri, Trisakti Handayani, and Agus Tinus. "Analisis Konsep Pemikiran Ki Hajar Dewantara Dalam Perspektif Pendidikan Karakter." Jurnal Civic Hukum 1, no. 1 (2016): 33. https://doi.org/10.22219/jch.v1i1.10460.

Sultoni, Ahmad, Alef Theria Wasim, and Aris Fauzan. "Development of Prophetic Intelligence (Phenomenology Study of Religious Transformation)." International Journal of Islamic Educational Psychology (IJIEP) 1, no. 1 (2020): https://doi.org/10.18196/ijiep.1102.

Tilaar, H.A.R. Pedagogik Teoritis Untuk Indonesia. Jakarta: Kompas, 2015.

Wiryopranoto, Suhartono. Perjuangan $K i$ Hajar Dewantara: Dari Politik Ke Pendidikan. Edited by Djoko Marihandono. Jakarta: Museum Kebangkitan Nasional Direktoral Jenderal Kebudauaan Kementerian Pendidikan dan Kebudayaan, 2017.

Yamin, Moh. Menggugat Pendidikan Indonesia, Belajar Dari Paulo Freire Dan Ki Hajar Dewantara. Yogyakarta: Ar-Ruzz Media, 2009.

Yanuarti, Eka. "Pemikiran Pendidikan Ki. Hajar Dewantara Dan Relevansinya Dengan Kurikulum 13." Jurnal Penelitian 11, no. 2 (2017): 237-66. https://doi.org/10.21043/jupe.v11i2.348 9. 